\title{
Oxidation of L-alanine by Potassium Ferrate (VI) in Alkaline Media-Kinetics and Mechanism Study
}

\author{
Chaochao Chen, Dan Wang, Jinhuan Shan* \\ College of Chemistry and Environmental Science, Hebei University, Key Laboratory of Analytical Science and \\ Technology of Hebei Province, Baoding, 071002 Hebei, China
}

*Corresponding Author: Jinhuan Shan, College of Chemistry and Environmental Science, Hebei University, Key Laboratory of Analytical Science and Technology of Hebei Province, Baoding, 071002 Hebei, China

\begin{abstract}
In this paper, the reaction kinetics of Potassium Ferrate (VI) with L-alanine was studied spectrophotometrically. The reaction was determined under alkaline condition at the temperatures rang of $298.2 \mathrm{~K}-318.2 \mathrm{~K}$ and the $\mathrm{pH}$ rang of 9.12 -10.27. All data was obtained from the pseudo-first order reaction. It was found that the reaction is a first-order for reactant. The observed rates constants $\left(k_{\text {obs }}\right)$ increased with the increase of [reductant], whereas the $k_{\text {obs }}$ decreased with the increase of $\left[\mathrm{OH}^{-}\right]$. The reaction is negative fraction order with respect to $\left[\mathrm{OH}^{-}\right]$. A plausible mechanism involving a slow reaction as the rate-controlling step is proposed and the rate equations derived from the mechanism can explain all the experimental results. The rate constants of the rate-controlling step and the thermodynamic activation parameters at $298.2 \mathrm{~K}$ were also calculated.
\end{abstract}

Keywords: Oxidation, Potassium Ferrate (VI), L-alanine,, Mechanism, Kinetics

\section{INTRODUCTION}

In recent years, potassium ferrate as a non-chlorine type waters treatment agent has been widely used in water pollution, It can not only quickly kill bacteria and viruses in water, but also can remove organic and inorganic contaminants from water and produce no carcinogenic substances such as chloroform and chlorophenol [1-6]. Ferrate (VI) is tetrahedral in structure, the feature of all Fe-O bonds is covalently. $\mathrm{Fe}(\mathrm{VI})$ sorts are strong oxidizing agents with an oxidation potential of $\mathrm{E}_{0}=+2.2 \mathrm{~V}$ in acidic media and $\mathrm{E}_{0}=+0.72 \mathrm{~V}$ in alkaline media [7]. Fe (VI) ion has maximum absorption wavelength at $508 \mathrm{~nm}$ in aqueous solution $\left(8508 \mathrm{~nm}=1150 \mathrm{~L} \cdot \mathrm{mol}^{-1} \cdot \mathrm{cm}^{-1}\right)$ [8], which is very commonly used to ensure its concentration.

In medicine, L-alanine is an important raw material for the synthesis of $\mathrm{VB}_{6}$, $\mathrm{L}$-alanine as the main component of the amino acid injection can be attending the liver, encephalopathy treatment, and promote rapid recovery of patients with hepatic coma, it is also a diuretic medicine. It can be used as flavor enhancer, increase seasoning seasoning effect; it can also be used as sour correction agent to improve the organic acid sour. In addition L-alanine can be used for biochemical research, tissue culture, liver function determination.

The reaction mechanism of Potassium Ferrate is divided into two kinds: one is one-electron pathway, the other is two-electron pathway [9-13]. Thus, according to the different reaction system, the reaction mechanism needs to be further studied. In this paper, we report the potassium ferrate oxidation of Lalanine, furthermore, the kinetics and reaction mechanisms were studied.

\section{EXPERIMENTAL}

\subsection{Materials}

Potassium Ferrate (VI) was synthesised by the oxidation of Fe (III) through hypochlorous acid and purified based on the reported method of Thompson etal [14]. All the matters used were of AR reagent grade. Solutions were prepared with water that had been doubly distilled. The buffer solution is prepared by mixing $\mathrm{Na}_{2} \mathrm{HPO}_{4}$ and $\mathrm{NaOH}$ proportionally. $\mathrm{KNO}_{3}$ and the buffer solution are used to adjust the ionic strength and hydroxide ion strength of the reaction system. The Potassium Ferrate 
(VI) solutions were prepared by adding solid samples of $\mathrm{KFeO}_{4}$ to buffer solutions and the phosphate was a complexing agent for Fe (III) that prevented precipitation of iron hydroxides which obstructs with the optical detecting of the reaction and promotes the self-decomposition of $\mathrm{Fe}$ (VI). A molar absorption at $508 \mathrm{~nm}\left(\varepsilon=1150 \mathrm{~L} \cdot \mathrm{mol}^{-1} \cdot \mathrm{cm}^{-1}\right)$ was used to calculate the concentration of potassium ferrate [8]. Reductant solutions was also prepared with buffer solutions.

\subsection{Methods}

The reaction rates were measured by following the decay of the ferrate peak at $508 \mathrm{~nm}$ on the SFM2000 stopped-flow spectrophotometer (Bio-Logic, France), which has a cell holder kept at constant temperature $\left( \pm 0.1^{\circ} \mathrm{C}\right)$ by circulating water from a thermostat (DC-2006, Baoding, China) and the experiments were under pseudo-first order conditions with L-alanine in excess. The reaction contains two major substances, that is the Potassium Ferrate (VI) serving as oxidant and the L-alanine as reductant. The concentration of $\mathrm{Fe}(\mathrm{VI})$ in the experiments was kept approximately constant at $2.0 \times 10^{-}$ ${ }^{4} \mathrm{~mol} \cdot \mathrm{L}^{-1}[15]$, while the L-alanine concentration ranged from $1.0 \times 10^{-2}$ to $5.0 \times 10^{-2} \mathrm{~mol} \cdot \mathrm{L}^{-1}$ and the $\mathrm{pH}$ ranged from 9.12 to 10.27 .

\subsection{Product Analysis}

When the reaction was carried out under the phosphate-buffered aerobic condition, there is no ferric oxy hydroxides precipitate in the solution. The presence of the Fe(III) was detected by adding the potassium thiocyanate to the waste solutions to produce the red ferric thiocyanate complex. Under the anaerobic conditions, the Fe (III) was therefore found to be the only iron species [16].

\subsection{Reaction Intermediate}

In order to prove that $\mathrm{Fe}$ (II) is the intermediate of the reaction, before the reaction begins, add the 1,10-phenanthroline to the reductant solution and then mix with the Ferrate(VI) solution to produce the orange red $\left[\mathrm{Fe}(\mathrm{phen})_{3}\right]^{2+}[17]$, apparently $\mathrm{Fe}(\mathrm{VI})$ is reduced to $\mathrm{Fe}$ (III) with $\mathrm{Fe}$ (II) stage.

\section{RESULTS AND DISCUSSION}

The reaction was investigated by measuring the absorbance of $\mathrm{Fe}(\mathrm{VI})$ at $508 \mathrm{~nm}$ wavelength as a function of time. Under the conditions of [reductant $]_{0}>>[\mathrm{Fe}(\mathrm{VI})]_{0}$, the plots of $\ln \left(\mathrm{A}_{\mathrm{t}}-\mathrm{A}_{\infty}\right)$ versus $\mathrm{t}$ were straight line, where $A_{t}$ is the absorbance at time $t$ and $A_{\infty}$ at infinite time. It indicates that the reaction is first order based on the characteristic of pseudo-first order. The pseudo-first order rate constants $k_{\mathrm{obs}}$ were calculated by the method of least squares $(\mathrm{r} \geq 0.998)$. The $k_{\mathrm{obs}}$ values were calculated by an average method on the basis of at least three parallel experiments, and the reproducibility was within $\pm 5 \%$.

\subsection{The Effect of [Reductant] on the Reaction Rates}

In the temperature range of $298.2 \mathrm{~K}-318.2 \mathrm{~K}$, When $[\mathrm{Fe}(\mathrm{VI})]$ and $\left[\mathrm{OH}^{-}\right]$were constant concentrations and ionic strength was $1.00 \mathrm{~mol} \cdot \mathrm{L}^{-1}$. The $k_{o b s}$ of the reaction were measured as a function of [reductant], It was found that the values of $k_{o b s}$ increase linearly with the increase of the reductant concentrations. The plots of $k_{o b s}$ versus [reductant] were linear and passed through the origin (Fig.1). Besides, the linear dependence observes a first-order term with reductant.

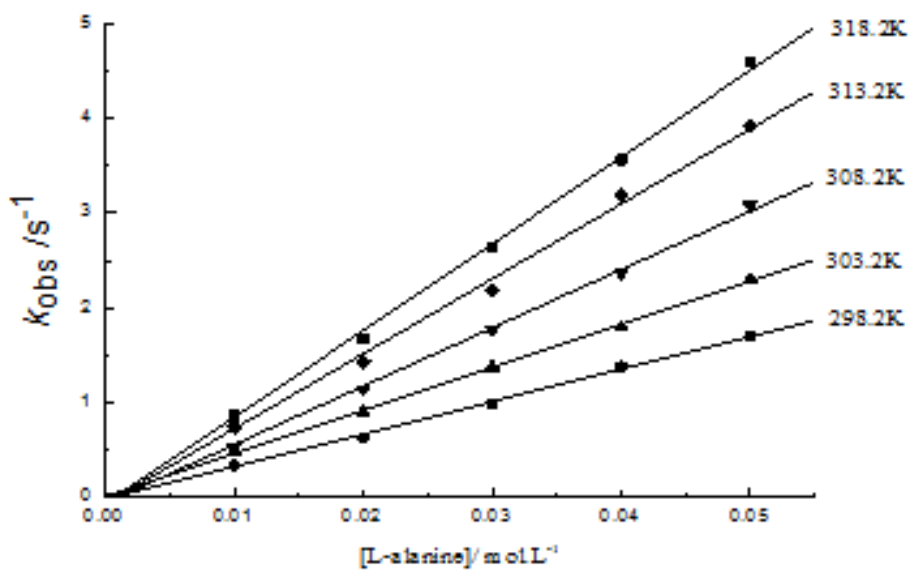

Fig1. Plots of $k_{o b s}$ versus [L-alanine] at diffirent temperatures. $[\mathrm{Fe}(\mathrm{VI})]=2.00 \times 10^{-4} \mathrm{~mol} \cdot \mathrm{L}^{-1},[\mathrm{OH}]=7.41 \times 10^{-}$ ${ }^{5} \mathrm{~mol} \cdot \mathrm{L}^{-1}, I=1.00 \mathrm{~mol} \cdot \mathrm{L}^{-1}, r \geq 0.998$. 


\subsection{The Effect of $\left[\mathrm{OH}^{-}\right]$on the Reaction Rates}

In the temperature range of $298.2 \mathrm{~K}-318.2 \mathrm{~K}$, When [Fe (VI)], [L-alanine] and ionic strength were constant, the $k_{o b s}$ decreased with the increase of $\left[\mathrm{OH}^{-}\right]$. The plot of $1 / k_{o b s}$ versus $\left[\mathrm{OH}^{-}\right]$was linear and the reaction order of $\left[\mathrm{OH}^{-}\right]$was found to be negative fractional (Fig 2).

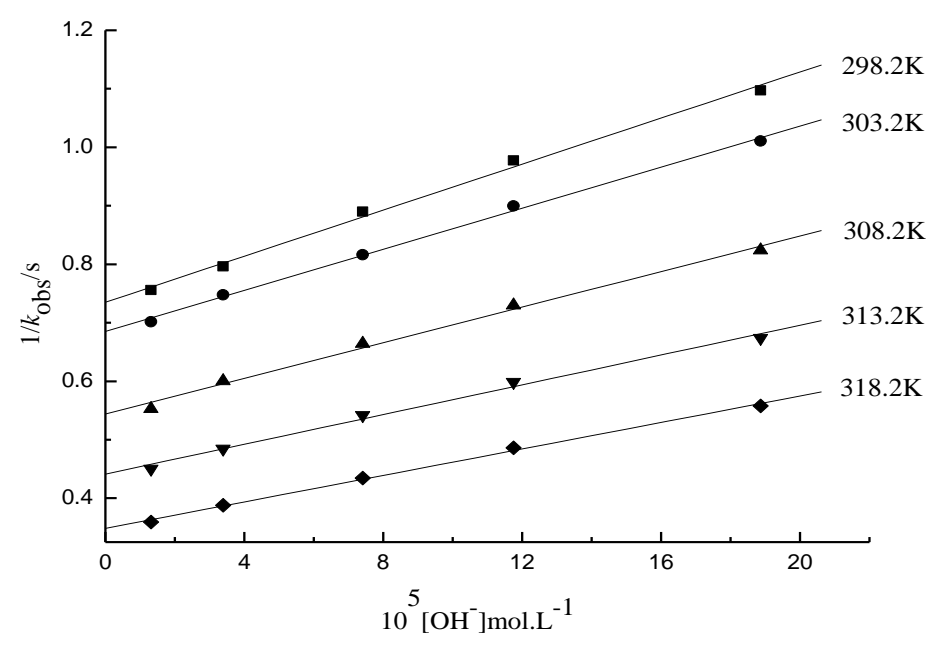

Fig2. Plots of $1 / \mathrm{k}_{\text {obs }}$ versus $\left[\mathrm{OH}^{-}\right]$at diffirent temperatures. $[\mathrm{Fe}(\mathrm{VI})]=2.00 \times 10^{-4} \mathrm{~mol} \cdot \mathrm{L}^{-1},[\mathrm{~L}$-alanine $]=3.00 \times 10^{-2}$ $\mathrm{mol} \cdot \mathrm{L}^{-1}, I=1.00 \mathrm{~mol} \cdot \mathrm{L}^{-1} \cdot r \geq 0.997$.

\subsection{Reaction Mechanism}

Since ferrate is a dibasic acid, it will undergo the following ionization:

$$
\begin{aligned}
& \mathrm{H}_{2} \mathrm{FeO}_{4} \rightleftharpoons \mathrm{HFeO}_{4}^{-}+\mathrm{H}^{+}, \mathrm{pK}_{\mathrm{a}_{1}}=3.5 \\
& \mathrm{HFeO}_{4}^{-} \rightleftharpoons \mathrm{FeO}_{4}^{2-}+\mathrm{H}^{+}, \mathrm{pK}_{\mathrm{a}_{2}}=7.8
\end{aligned}
$$

Under the condition of this experiment, according to the value of $p k_{a 2}$, there exists only the form of equation (2). It is assumed that $\mathrm{HFeO}_{4}{ }^{-}$is an active reaction component and decreases with the increase of $\mathrm{pH}$. In fact, it has been proved from this study that $\mathrm{HFeO}_{4}^{-}$is most likely to be a reactive species.

Under alkaline conditions, $\mathrm{FeO}_{4}{ }^{2-}$ will be partially hydrolyzed:

$$
\mathrm{FeO}_{4}^{2-}+\mathrm{H}_{2} \mathrm{O} \rightleftharpoons \mathrm{HFeO}_{4}^{-}+\mathrm{OH}^{-}
$$

Hence:

$$
K_{\mathrm{h}}=\frac{\left[\mathrm{HFeO}_{4}^{-}\right]\left[\mathrm{OH}^{-}\right]}{\left[\mathrm{FeO}_{4}^{2-}\right]}=\frac{K_{\mathrm{w}}}{K_{\mathrm{a}_{2}}}=6.31 \times 10^{-7}
$$

Therefore:

$$
\frac{\left[\mathrm{HFeO}_{4}^{-}\right]}{\left[\mathrm{FeO}_{4}^{2-}\right]}=\frac{K_{\mathrm{h}}}{\left[\mathrm{OH}^{-}\right]}
$$

Obviously, the concentration of $\mathrm{HFeO}_{4}^{-}$decreases with the increase $\left[\mathrm{OH}^{-}\right]$, and was very small, However, $\mathrm{HFeO}_{4}^{-}$is very easy to form a highly active complex with reductant through the $\mathrm{H}$ atom. Under the attack of the hydroxyl ion, the complex decomposes into Fe (IV) and the product, and then $\mathrm{Fe}$ (IV) reacts further with the reductant to form $\mathrm{Fe}$ (II) and the product. Therefore, the reaction is mainly achieved by $\mathrm{HFeO}_{4}$. 
According to a series of discussions, the mechanism may be written as shown:

$$
\begin{aligned}
& \mathrm{FeO}_{4}^{2-}+\mathrm{H}_{2} \mathrm{O} \stackrel{k_{\mathrm{h}}}{\rightleftharpoons} \mathrm{HFeO}_{4}^{-}+\mathrm{OH}^{-} \\
& \mathrm{HFeO}_{4}^{-}+\mathrm{R} \underset{k_{-2}}{\stackrel{k_{2}}{\rightleftharpoons}} \mathrm{X} \\
& \mathrm{X}+\mathrm{OH}^{-} \stackrel{k_{3}}{\longrightarrow} \mathrm{Fe}(\mathrm{IV})+\text { Products } \\
& \mathrm{Fe}(\mathrm{IV})+\mathrm{R} \stackrel{k_{4}}{\longrightarrow} \mathrm{Fe}(\mathrm{II})+\text { Products } \\
& \mathrm{Fe}(\mathrm{IV})+\mathrm{Fe}(\mathrm{II}) \stackrel{k_{5}}{\longrightarrow} 2 \mathrm{Fe}(\mathrm{III})
\end{aligned}
$$

The equation (4) is the rate-determing step, where $\mathrm{R}$ stands for reductant. The rate law of the reaction was derived as follows:

$$
-\frac{\mathrm{d}\left[\mathrm{FeO}_{4}^{2-}\right]}{\mathrm{dt}}=k_{2}\left[\mathrm{HFeO}_{4}^{-}\right][\mathrm{R}]-k_{-2}[\mathrm{X}]
$$

$[\mathrm{X}]$ can be got on the basis of static state method and equation of (4) and (5):

$$
[\mathrm{X}]=\frac{k_{2}\left[\mathrm{HFeO}_{4}^{-}\right][\mathrm{R}]}{k_{-2}+k_{3}\left[\mathrm{OH}^{-}\right]}
$$

According to equation (8) and (9), we get equation (10

$$
-\frac{\mathrm{d}\left[\mathrm{FeO}_{4}^{2-}\right]}{\mathrm{dt}}=\frac{k_{2} k_{3}\left[\mathrm{HFeO}_{4}^{-}\right][\mathrm{R}]\left[\mathrm{OH}^{-}\right]}{k_{-2}+k_{3}\left[\mathrm{OH}^{-}\right]}
$$

Based on equation (3), equation (11) will be obtained:

$$
\left[\mathrm{HFeO}_{4}^{-}\right]=\frac{K_{\mathrm{h}}\left[\mathrm{FeO}_{4}^{2-}\right]}{\left[\mathrm{OH}^{-}\right]}
$$

Substituting equation (11) into equation (10), we can get equation (12)

$$
-\frac{\mathrm{d}\left[\mathrm{FeO}_{4}^{2-}\right]}{\mathrm{dt}}=\frac{k_{2} k_{3} K_{\mathrm{h}}\left[\mathrm{FeO}_{4}^{2-}\right][\mathrm{R}]}{k_{-2}+k_{3}\left[\mathrm{OH}^{-}\right]}=\frac{k_{2} k_{3} K_{\mathrm{h}}[\mathrm{R}]}{k_{-2}+k_{3}\left[\mathrm{OH}^{-}\right]}\left[\mathrm{FeO}_{4}^{2-}\right]
$$

Hence:

$$
k_{\mathrm{obs}}=\frac{k_{2} k_{3} K_{\mathrm{h}}[\mathrm{R}]}{k_{-2}+k_{3}\left[\mathrm{OH}^{-}\right]}=\frac{k_{2} k^{\prime} K_{\mathrm{h}}[\mathrm{R}]}{1+k^{\prime}\left[\mathrm{OH}^{-}\right]}
$$

Where

$$
k^{\prime}=\frac{k_{3}}{k_{-2}}
$$

Taking reciprocal of equation (13) we get equation (14)

$$
\frac{1}{k_{\mathrm{obs}}}=\frac{1+k^{\prime}\left[\mathrm{OH}^{-}\right]}{k_{2} k^{\prime} K_{\mathrm{h}}[\mathrm{R}]}=\frac{1}{k_{2} k^{\prime} K_{\mathrm{h}}[\mathrm{R}]}+\frac{\left[\mathrm{OH}^{-}\right]}{k_{2} K_{\mathrm{h}}[\mathrm{R}]}
$$

It is clear from the equation (12) that the oxidation-reduction reaction is first-order to that of potassium ferrate and L-alanine. In addition the $k_{o b s}$ decreased with the increase of $\left[\mathrm{OH}^{-}\right]$and $1 / k_{o b s}$ versus $\left[\mathrm{OH}^{-}\right]$was linear by the equation (14), which was consistent with the experimental phenomena. Basing on the equation (14) and the slopes of figure 2, the rate-determing step constants $\left(k_{2}\right)$ were evaluated and the relational activation parameters date were obtained (Table 2) [18]. 
Table2. Rate constants of $\left(k_{2}\right)$ and activation parameters of the rate-determing step

\begin{tabular}{|l|c|c|c|c|c|}
\hline $\mathrm{T}(\mathrm{K})$ & 298.2 & 303.2 & 308.2 & 313.2 & 318.2 \\
\hline$k_{2} \cdot 10^{-4}\left(\mathrm{~mol}^{-1} \cdot \mathrm{L} \cdot \mathrm{s}^{-1}\right)$ & 2.69 & 3.01 & 3.48 & 4.16 & 4.68 \\
\hline $\begin{array}{l}\text { Thermodynamic activation } \\
\text { parameters }(298.2 \mathrm{~K})\end{array}$ & $\mathrm{Ea} /\left(\mathrm{kJ} \cdot \mathrm{mol}^{-1}\right)=22.60, \Delta \mathrm{H}^{\ddagger} /\left(\mathrm{kJ} \cdot \mathrm{mol}^{-1}\right)=20.12$, \\
$\Delta \mathrm{S}^{\ddagger} /\left(\mathrm{J} \cdot \mathrm{K}^{-1} \cdot \mathrm{mol}^{-1}\right)=-93.25$
\end{tabular}

The plots of $\ln _{2}$ versus 1/T have the following intercept (a), slope (b) and relative coefficient $(r): a=19.30, b=-$ $2718.79, r=0.996$

\section{CONCLUSION}

On the basis of the above research and related results, we can get the following conclusion. (1) Each oxidation is assumed to occur through a two-electron pathway. First the Fe (VI) reacts with a molecule of reductant to form complex X. Then, the X dissociates into Fe (IV) and products under the attack of hydroxyl. The Fe (IV) with another molecule of reductant to form Fe (II) and products. Finally, The Fe (IV) reacts with Fe (II) to form Fe (III). (2) Under the pseudo-first condition, the reaction is first-order with respect to oxidant and reductant, and to $\mathrm{OH}^{-}$is negative fractional. (3) The activation energy of reaction is small, while the entropy of activation has more negative values, so the reaction rate is not particularly fast [18]. The function of $\left[\mathrm{OH}^{-}\right]$and the activation parameters are consistent with experimental phenomena and provide the basis for kinetics studies.

\section{REFERENCES}

[1] Graham N., Jiang C.C. and Li X.Z., The influence of pH on the degradation of phenol and chlorophenols by potassium ferrate, Chemosphere. 56(10), 949-956 (2004).

[2] Ma J. and Liu W., Effectiveness and mechanism of potassium ferrate(VI) preoxidation for algae removal coagulation, Water Research. 36(4), 871-878 (2002).

[3] Ruben A.R. and Frank J.M., Oxidation of thioacetamide by Ferrate(VI), Marine Chemistry. 70(1), 235-242 (2000).

[4] Yunho Lee., Jeyong Yoon and Urs Von Gunten, Kinetics of the Oxidatin of phenols and phenolic Endocrine Disruptors during Water Treatment with Ferrate (VI), Environ. Sci. Technol. 39, 8978-8984 (2005).

[5] Sharma V.K., Radek Zboril and Varma R.S., Ferrates: Greener Oxidants with Multimodal Action in Water Treatment Technologies, Acc. Chem. Res. 48(2), 182-191 (2015).

[6] Umid Man Joshi, Rajasekhar Balasubramanian and Sharma V.K., Potential of Ferrate (VI) in Enhancing Urban Runoff Water Quality, ACS Symposium Series. 985(30), 466-476 (2008).

[7] Wood R.H., The Heat, Free Energy and Entropy of the Ferrate(VI) Ion, J. Am. Chem. Soc. 80(9), 20382041 (1958).

[8] Shan J.H. and Yang Y.F., Kinetics and Mechanism of Oxidation of Iso-propanolamine and Isobutanolamine by Potassium Ferrate, Asian Journal of Chemistry. 24(1), 377-381 (2012).

[9] Goff H. and Murmann R.K., Studies on mechanism of isotopic oxygen exchange and reduction of Ferrate(VI) ion $\left(\mathrm{FeO}_{4}{ }^{2-}\right)$, J. Am. Chem. Soc. 93(23), 6058-6065 (1971).

[10] Johnson M.D., Hornstein B.J. and Wischnewsky J., Ferrate (VI) Oxidation of Nitrogenous Compounds, ACS Symposium Series. 985(12), 177-188 (2008).

[11] Sharma V.K. and Bielski B. H.J., Reactivity of Ferrate (VI) and Fe(V) with amino acids, Inorg. Chem. 30, 4306-4310 (1991).

[12] Johnson M.D. and Homstein B.J., Unexpected selectivity in the oxidation of arylamines with ferratepreliminary mechanistic considerations, Chem Commun. 8, 965-966 (1996).

[13] Huang H., Sommerfeld D., Dunn B.C. Uoyd C.R Eyring and E.M., Ferrate (VI) oxidation of aniline, Dalton Trans. 8, 1303-1305 (2001).

[14] Thompson G.W., Ockerman L.T. and Schreyer J.M., Preparation and Purification of Potassium Ferrate (VI), J. Am. Chem. Soc. 73(3), 1379-138 (1951).

[15] John F.Read*, Sharon A.Bewick, Christopher R.Graves, et al The kinetics and mechanism of the oxidation of S-methyl-L-cysteine, L-cystine and L-cysteine by potassium ferrate, Inorganica, Chimica. Acta. 303, 244-255 (2000).

[16] Johnson M.D. and Read J.F., Kinetics of the Ferrate Oxidation of Thiosulfate and Other Sulfur-Containing Species, Inorg. Chem. 35, 6795-6799 (1996). 
[17] Carr J.D., Kelier P.B., et al Proceedings of Conference on Water Chlorination Chemistry Environment Impact Health Effects, Proc. Conf. 5, 1285-1298 (1985).

[18] Shan J.H., Han J., Y. LI and Zhang Z.W., The Oxidation of 2-(2-Methoxyethoxy)-ethanol and 2-(2Ethoxyethoxy)-ethanol by Ditelluratocuprate (III) in Alkaline Medium, Asian Journal of Chemistry. 26(14), 4347-4350 (2014).

Citation: C.C. Chen, "Oxidation of L-alanine by Potassium Ferrate (VI) in Alkaline Media-Kinetics and Mechanism Study", International Journal of Advanced Research in Chemical Science (IJARCS), vol. 4, no. 7, pp. 1-6, 2017. http://dx.doi.org/10.20431/2349-0403.0407001

Copyright: (C) 2017 Authors. This is an open-access article distributed under the terms of the Creative Commons Attribution License, which permits unrestricted use, distribution, and reproduction in any medium, provided the original author and source are credited. 